\title{
Express Yourself or Stay Mystery? The Effect of Self-Disclosure on Entrepreneurial Identity of Team Members
}

\author{
Yun Duan, Yangyu Zhang*, Jingjing Zhang \\ School of Management, Shanghai University, Shanghai, China \\ Email: *kellyboy@shu.edu.cn
}

How to cite this paper: Duan, Y., Zhang, Y.Y. and Zhang, J.J. (2018) Express Yourself or Stay Mystery? The Effect of Self-Disclosure on Entrepreneurial Identity of Team Members. Open Journal of Social Sciences, 6, 204-218.

https://doi.org/10.4236/jss.2018.612018

Received: December 5, 2018

Accepted: December 25, 2018

Published: December 28, 2018

Copyright ( 92018 by authors and Scientific Research Publishing Inc. This work is licensed under the Creative Commons Attribution International License (CC BY 4.0).

http://creativecommons.org/licenses/by/4.0/

\begin{abstract}
The entrepreneurial identity of team members is vital to team stability and entrepreneurial success. How to improve the identity of team members is a significant issue for entrepreneurs to ponder. Combining literature analysis and empirical research, this paper discusses the following issues: 1) Whether the entrepreneur's self-disclosure has a positive impact on the members' entrepreneurial identity; 2) The internal mechanism of how entrepreneur's self-disclosure affects the team members' entrepreneurial identity. The results show that in the context of entrepreneurship in China, the self-disclosure of entrepreneurs can promote the entrepreneurial identity of the team members, and the entrepreneurial passion mediates the relationship between them.
\end{abstract}

\section{Keywords}

Entrepreneurship, Self-Disclosure, Emotional Contagion, Entrepreneurial Identity, Entrepreneurial Passion

\section{Introduction}

Entrepreneurship is like "thousands of horses crossing a single bridge", and only a few can survive and develop in the fierce competition. In this process, the entrepreneur's personal abilities are often limited, and entrepreneurial success depends largely on the team's success [1]. Numerous studies have shown that entrepreneurial identity is the soul of a successful entrepreneurial team [2]. A high level of entrepreneurial identity is critical to the coordination and cooperation of the entrepreneurial team. As the leader of the entrepreneurial team, it is very necessary for the entrepreneur to enhance the entrepreneurial identity of the team members in order to maximize the effectiveness of the entrepreneurial 
team.

A high level of entrepreneurial identity must be based on adequate and effective communication and information sharing [3]. Psychologists claimed that self-disclosure is an important way to communicate and maintain interpersonal relationships. Social Penetration Theory also put forward that self-disclosure is the core of relationship development. The depth and breadth of self-disclosure directly affect the strength and quality of inter-individual relationships. Therefore, in the context of entrepreneurship, self-disclosure does promote relationships and deepen communication between members. Since entrepreneurial teams are confronted with more complex environments and greater risks than ordinary teams, how to increase the entrepreneurial identity of team members through self-disclosure is particularly important for entrepreneurs in the Chinese context where "relationship" means a lot.

However, the self-disclosure of entrepreneurs is not always a good thing. Positive self-disclosure, while enhancing the cohesiveness of team members, will also weaken the sense of distance between superiors and subordinates, thus causing inconvenience to team management; while negative self-disclosure will release the pressure of entrepreneurs themselves, the negative emotions can also "infect" team members [4], which undermines the team members' recognition of the entrepreneur's authority and professionalism. In view of this, how can entrepreneurs control the content and extent of self-disclosure in order to maximize entrepreneurial identity? Taking this question into account, this paper focuses on the intrinsic mechanism between entrepreneurs' self-disclosure and entrepreneurial identity of team members, and it aims to explore that how does the content and degree of entrepreneurs' self-disclosure affect the active follow-up of entrepreneurial team members and give some useful inspiration to entrepreneurial teams.

The process of conducting this paper began first with reviewing and analyzing the related literature, theories and relevant concepts constructs. Then we investigated the relationships between them, which developed the research hypotheses and ultimately led to the formation of the research conceptual model. The second section solves with the research methodology. By taking all factors into consideration, we select and determine the most suitable measurement model and reviews were indicative of the reliability and validity of the measurements. The third section refers to a report and discussion of the results from the analysis of the structural model and the hypotheses tests.

\section{Theoretical Foundations and Hypotheses}

\subsection{Self-Disclosure and Entrepreneurial Identity}

Self-disclosure means that individuals volunteered to share information about their feelings, thoughts, attitudes, emotions and experiences to others [5], and the content contained in self-disclosed information that can help others have a more comprehensive understanding to things they did not know before, then 
reduce misunderstandings caused by insufficient understanding, as well as maintain and develop intimate relationships better. According to the content of self-disclosure, it can be divided into descriptive disclosure and evaluative disclosure [6]. Among them, descriptive self-disclosure is to share objective information with others. In the context of entrepreneurship, the descriptive self-disclosure of entrepreneurs mainly includes the sharing of objective entrepreneurial information, such as entrepreneurial fund status, family relationship, work experience, etc. While evaluative self-disclosure refers to sharing subjective emotions or preferences with others, such as self-evaluation and inner feelings of entrepreneurs. Emotional disclosure is a typical evaluative self-disclosure.

Entrepreneurial identity refers to the recognition of entrepreneurial team members on the role of entrepreneurs and entrepreneurial career [7]. To be specific, entrepreneurial identity is generally reflected in trusting the personality and leadership of entrepreneurs and recognizing the value of their entrepreneurial undertakings, so as to continuously and faithfully follow entrepreneurs. Entrepreneurial teams with high-level entrepreneurial identity are more likely to "pull together". From the perspective of the Information Theory, in the process of information communication, entrepreneurs strengthen information communication and eliminate doubts of team members through the expression of language, emotion, posture, gesture and facial expression in self-disclosure, and then promote the team members' recognition of entrepreneurs.

In essence, self-disclosure is an information exchange activity. Self-disclosure allows information to be shared and improves team members' cognitive consistency. According to the Social Penetration Theory, in a conversation, when A conveys the message, B will give feedback and then form a two-way information interaction [8]. The process of self-disclosure is accompanied by a sense of attraction and identity. When people share their information with others, others will be attracted and rewarded by means of feedback. It can be seen that the entrepreneur's proper self-disclosure can not only gain the recognition of team members, but also relieve the pressure of entrepreneurs in the process of starting a business. Psychologists argued that identity is a process of internalization of emotions. In interpersonal interactions, individuals are affected by the others' emotion. This two-way influence belongs to identity [9]. Therefore, we suggest that entrepreneurial self-disclosure has a positive impact on the team members' entrepreneurial identity.

Hypothesis 1: Entrepreneur's self-disclosure has a positive impact on team members' entrepreneurial identity.

Hypothesis 1a: The descriptive self-disclosure of entrepreneurs has a positive impact on the entrepreneurial identity of team members.

Hypothesis $1 b$ : The evaluative self-disclosure of entrepreneurs has a positive impact on the entrepreneurial identity of team members.

\subsection{Self-Disclosure and Entrepreneurial Passion}

Entrepreneurial passion refers to the positive emotions that individuals expe- 
rience in entrepreneurial practice. In other words, it reflects the individual's love and dedication to entrepreneurial activities [10]. The entrepreneurial passion involved in this paper refers to the perception of the entrepreneurial team members' passion for entrepreneurs, that is, the entrepreneurial passion of entrepreneurs is evaluated from the perspective of employees. Based on the Emotional Contagion Theory, Breugst (2012) analyzed the impact of entrepreneurial passion on employees, and found that the entrepreneurial enthusiasm perceived by employees comes from the common goal and value sharing by managers. Some studies have found entrepreneurial passion is the positive emotion generated by individual entrepreneurial behavior (such as using more innovative ideas to cope with various challenges) [11], and there are also some studies explored how this positive emotion acts on the cognition of other stakeholders (such as entrepreneurial team members) [12]. Based on the Grounded Theory Method, Yitshaki and Kropp (2016) investigated the life stories of 45 high-tech entrepreneurial teams and found that the entrepreneurial enthusiasm perceived by employees and the information sharing by managers is an iterative cyclical process, and information sharing and passion are interacting and increasing constantly [13].

In general, the sharing of information such as managerial goals and values is achieved through self-disclosure. On the one hand, entrepreneurs give access to team members having a more comprehensive understanding of the objective entrepreneurial environment through descriptive disclosure, this information will affect the team members' overall perception and evaluation of entrepreneurs; On the other hand, evaluative disclosure is a kind of emotional expression. During the entrepreneurial process, entrepreneurs will show their emotions, such as excitement, fear, anxiety, etc., to their subordinates. It has been found that entrepreneurial team members can feel the entrepreneurial passion through the emotions and actions of entrepreneurs. This passion represents the entrepreneur's confidence and commitment to the company, and also reflects the entrepreneur's status and the current situation of enterprise management to a certain extent [14]. It can be inferred that the self-disclosure of entrepreneurs may do good to enhance the perception of team members' passion for entrepreneurs.

Hypothesis 2: Entrepreneur's self-disclosure has a positive impact on the perception of team members on entrepreneurial passion.

Hypothesis 2a: The descriptive self-disclosure of entrepreneurs has a positive impact on the perception of team members on entrepreneurial passion.

Hypothesis $2 b$ : The evaluative self-disclosure of entrepreneurs has a positive impact on the perception of team members on entrepreneurial passion.

\subsection{Entrepreneurial Passion Acts as an Mediator}

Previous studies have found that self-disclosure of entrepreneurs can stimulate the passion perception of team members and thus promote the entrepreneurial identity of team members [15]. The generation and enhancement of entrepre- 
neurial passion is one of the key ways for entrepreneurs' self-disclosure to promote the formation of entrepreneurial identity of team members. Entrepreneurs' self-disclosure helps team members form the sense of responsibility of "starting a business for themselves, and such entrepreneurial atmosphere is conducive to the formation of entrepreneurial identity of team members. Behavioral psychologists found that when entrepreneurs show their ability to conduct business activities under a good business environment, team members will quickly infected by the entrepreneurial passion, and then more willing to put its own resources and energy in entrepreneurial activity. As time goes by, there will be a sense of identity with the brainstorming of entrepreneurial activities [16]. As a consequence, with the infection of entrepreneurial passion, entrepreneurs' self-disclosure will promote the creation of team members' entrepreneurial identity.

Entrepreneur self-disclosure promotes the identity of entrepreneurial team members to entrepreneurs, and entrepreneurial passion plays an important role in this process. On the one hand, entrepreneurs' passion for entrepreneurship can be influenced by the individual's cognitive structure through the disclosure of their knowledge, skills and resources [16]. In other words, through descriptive disclosure, entrepreneurs are very likely to improve the evaluation of entrepreneurs by team members, and then enhance their confidence to entrepreneurial success, strengthen the team members' perception of entrepreneurial passion, and obtain the entrepreneurial identity of team members. On the other hand, evaluative expressions are mostly emotional expressions.

Emotional Contagion Theory holds that emotions are contagious. In the entrepreneurial context, entrepreneurs, as the main source of information, are more likely to infect other members of the team with their emotions and influence their sense of identity through information transmission [17]. Entrepreneur's evaluative self-disclosure can better promote team members' perception of entrepreneurial passion. In turn, team members are willing to support the entrepreneur's philosophy and recognize the company's values. These are the prerequisites for the formation of entrepreneurial identity. Studies have found that entrepreneurial passion plays an important role in promoting entrepreneurial identity. The more passion the team members perceive, the stronger the entrepreneurial identity will be [18]. As a result, through the display of objective information or emotions, the entrepreneurial passion of entrepreneurs can be intuitively perceived by team members, so as to enhance the team members' recognition of entrepreneurs and entrepreneurial career.

Hypothesis 3: Team members' perception of entrepreneurs' passion acts as an mediator in the relationship between self-disclosure of entrepreneurs and entrepreneurial identity of team members.

Hypothesis 3a: Team members perception of entrepreneurs passion acts as an mediator in the relationship between entrepreneurs descriptive disclosure and entrepreneurial identity of team members.

Hypothesis 3b: Team members perception of entrepreneurs passion acts as 
an mediator in the relationship between entrepreneurs' evaluative disclosure and entrepreneurial identity of team members.

The theoretical model of this paper is shown in Figure 1.

This paper collects data through questionnaires, and uses SPSS19.0 to verify the hypothesis proposed above by multiple linear regression methods. Among them, the test of mediating effect not only adopts multiple linear regression, but also uses Bootstrap method to further verify.

\section{Research Methods}

\subsection{Participants and Procedures}

Based on the research of Miller and Steier [19], this paper focuses on the entrepreneurial enterprises in the context of China. Since the research objects in this paper are new ventures, we select a small enterprise with 5 to 50 people as a sample. In addition, Shanghai is located in the south and Henan in the north of China. The selection of the two is well represented. Besides, Shanghai, as a typical international city, has hundreds of entrepreneurial parks, while Henan doesn't have so many start-ups, but the number is growing fast in recent years. As a consequence, the sample resources of both areas are easy to obtain. To make a combination of representation and availability, we collected data from the start-up teams of 5 to 50 people in Shanghai and Henan Province by visiting entrepreneurial teams. And the purpose of this study is to explore the influence mechanism of entrepreneurs' self-disclosure on team members' entrepreneurial identity, this study adopts a sample survey method rather than a comprehensive survey. The specific steps are as follows: First, based on isometric sampling, we selected 45 start-up parks in Henan and 45 in Shanghai. Secondly, through the selected entrepreneurial parks, the number of companies with 5 to 50 people was selected. Finally, In order to ensure that all enterprises are of different types, we picked 3 companies from them at random after classification. In this way, we distributed a total of 270 questionnaires 234 of them were returned. After eliminating the invalid questionnaires such as missing answers, we finally got 216 valid questionnaires, representing a response rate of $80 \%$. All participants were from start-ups in Shanghai and Henan provinces, including 130 males, accounting for $60.2 \%$ and 86 females, accounting for $39.8 \%$. Participants were mainly aged between 22 and 35 years old, accounting for $82.3 \%$ of the total.

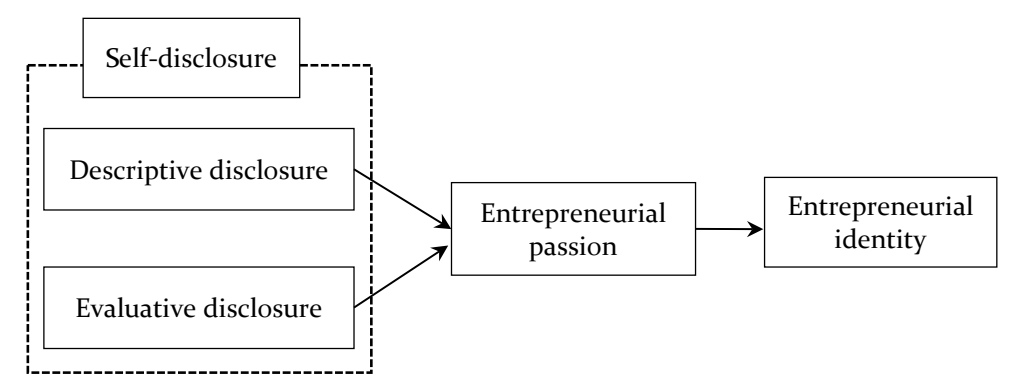

Figure 1. Theoretical model. 


\subsection{Measures}

The variables involved in this study include self-disclosure, entrepreneurial passion and entrepreneurial identity. To ensure that the questionnaire has high content validity, all scales we used are developed maturity scales. For the English scale, we translated particular questions back and forth with purpose to ensure the adaptability of the accuracy of the information.

Self-disclosure. The scale developed by Jourard (1971) was used for reference [20]. The scale is divided into two dimensions, descriptive disclosure and evaluative disclosure. In particular, the descriptive disclosure includes 9 items such as "the company's profitability, while evaluation disclosures include 3 items such as "the boss feels pressured during the operation of the company". Respondents were instructed to rate their perception on a five-point Likert scale ranging from $1=$ hardly speak to $5=$ strongly agree. The Cronbach's alpha coefficient in this study was 0.93

Entrepreneurial passion. To measure participants' perceived entrepreneurial passion, we used the scale prepared by Cardon [21]. Including 5 items such as "the boss manage our companies with a positive attitude". Responses ranged from 1 (strongly disagree) to 5 (strongly agree). In this investigation, the Cronbach's alpha coefficient was 0.943 .

Entrepreneurial identity. For the entrepreneurial identity, we refer to the scale developed by Kasperova and Kitching [22]. It includes team members' recognition of entrepreneurs and their recognition of start-ups. For instance, there are 7 items such as "I'm proud to work for the company", "our boss is a good leader", and they were rated from $1=$ strongly disagree to $5=$ strongly agree. In this study, the Cronbach's alpha coefficient is 0.906 .

Control variables. In order to reveal the relationship between self-disclosure more clearly, entrepreneurial passion and entrepreneurial identity, this study controls some important variables, including the gender of entrepreneurs $(1=$ male, 2 = female), age, education level $(1=$ High school, 2 = Junior college, $3=$ Undergraduate, $4=$ Graduate and above) and enterprise scale.

\subsection{Reliability and Validity}

The reliability of the questionnaire was investigated by using both the homogeneity reliability (Cronbach's alpha coefficient) and the CITC double test. The results show that the CITC values of all items are greater than 0.5 and the Cronbach's alpha coefficient is greater than 0.7 , and the Cronbach's alpha coefficient of each variable is greater than 0.8 , indicating that the internal consistency of the questionnaire is better.

For the validity, firstly, we used SPSS19.0 for confirmatory factor analysis (CFA) to test the structural validity of the questionnaire, and performed KMO index and spherical test (Bartlett's Test of Spherieity) on the sample. The result revealed that the KMO value of the questionnaire is 0.874 , which is greater than 0.7 , and the significant probability of Bartlett's spherical test is 0.000 , less than 
0.001 , which indicates that the data collected by the questionnaire is suitable for factor analysis.

Secondly, as shown in Table 1, the data also shows that the factor load of most items is greater than 0.7 , the minimum factor load is 0.653 , and the KMO of each scale is greater than 0.7 , indicating that the variable aggregation efficiency is better. In addition, the AVE square and CR combined reliability values of each variable are also basically greater than the correlation coefficient, thus, the variable discriminant validity is good. In conclusion, the analyze reveals that this model has a clear structure and significant importance, and has good aggregation validity and distinction validity.

Table 1. CITC, Factor loading, KMO, Cronbach's $\alpha$.

\begin{tabular}{|c|c|c|c|c|c|}
\hline & Item & CITC & Factor loading & $\mathrm{KMO}$ & Cronbach's $\alpha$ \\
\hline \multirow{12}{*}{ Self-disclosure } & M1 & 0.608 & 0.653 & \multirow{12}{*}{0.882} & \multirow{12}{*}{0.930} \\
\hline & $\mathrm{P} 2$ & 0.714 & 0.770 & & \\
\hline & M3 & 0.697 & 0.771 & & \\
\hline & $\mathrm{P} 4$ & 0.713 & 0.750 & & \\
\hline & M5 & 0.726 & 0.765 & & \\
\hline & M6 & 0.684 & 0.738 & & \\
\hline & M7 & 0.732 & 0.773 & & \\
\hline & M8 & 0.642 & 0.691 & & \\
\hline & M9 & 0.695 & 0.735 & & \\
\hline & P10 & 0.742 & 0.777 & & \\
\hline & M11 & 0.720 & 0.773 & & \\
\hline & M12 & 0.696 & 0.760 & & \\
\hline \multirow{5}{*}{$\begin{array}{l}\text { Entrepreneurial } \\
\text { passion }\end{array}$} & $\mathrm{J} 1$ & 0.845 & 0.855 & \multirow{5}{*}{0.885} & \multirow{5}{*}{0.940} \\
\hline & $\mathrm{J} 2$ & 0.841 & 0.832 & & \\
\hline & $\mathrm{J} 3$ & 0.836 & 0.853 & & \\
\hline & $\mathrm{J} 4$ & 0.834 & 0.832 & & \\
\hline & J5 & 0.869 & 0.863 & & \\
\hline \multirow{6}{*}{$\begin{array}{l}\text { Entrepreneurial } \\
\text { identity }\end{array}$} & R9 & 0.823 & 0.850 & \multirow{6}{*}{0.822} & \multirow{6}{*}{0.912} \\
\hline & R10 & 0.728 & 0.779 & & \\
\hline & R11 & 0.785 & 0.801 & & \\
\hline & R12 & 0.813 & 0.866 & & \\
\hline & R14 & 0.777 & 0.850 & & \\
\hline & R15 & 0.627 & 0.695 & & \\
\hline \multicolumn{4}{|c|}{ Total KMO value and Cronbach's $\alpha$ of the scale } & 0.874 & 0.913 \\
\hline
\end{tabular}

Note: since the factor load of R13 is $0.462<0.5$, the data in the table are obtained after excluding this item for analysis. 


\section{Results}

\subsection{Correlation Analyses}

The descriptive statistics and correlations among gender, age, education, firm size, self-disclosure, descriptive disclosure, evaluative disclosure, entrepreneurial passion and entrepreneurial identity are presented in Table 2. As shown in Table 2, except that descriptive disclosure has no significant correlation with entrepreneurial identity $(r=0.123, p>0.05)$, self-disclosure is positively correlated with entrepreneurial passion $(\mathrm{r}=0.247, \mathrm{p}<0.01)$ and entrepreneurial identity $(r=0.136, p<0.01)$. In addition, entrepreneurial passion is also positively correlated with entrepreneurial identity $(r=0.545, \mathrm{p}<0.01)$, which provides initial support for most hypotheses in this paper and indicates that our research is in the right direction.

\subsection{Regression Analyses}

This study used hierarchical regression analysis (Hox, 2010) [23] to verify the above assumptions. The results of the analysis are shown in Table 3.

Main effect test. Model 5 is a regression model of control variables for entrepreneurial identity. On this basis, model 6 , model 7 and model 8 are obtained by adding independent variables, self-disclosure, descriptive disclosure and evaluative disclosure. From model 6 , it can be seen that self-disclosure has a significant positive impact on entrepreneurial identity $(\beta=0.143, \mathrm{p}<0.05)$, which supports

Table 2. Mean, SD and correlation coefficients, AVE and CR values.

\begin{tabular}{|c|c|c|c|c|c|c|c|c|c|}
\hline Variable & 1 & 2 & 3 & 4 & 5 & 6 & 7 & 8 & 9 \\
\hline 1) Sex & - & & & & & & & & \\
\hline 2) Age & -0.066 & - & & & & & & & \\
\hline 3) Edu. & 0.002 & $-0.367^{\star \star}$ & - & & & & & & \\
\hline 4) Size & -0.112 & $0.321^{\star *}$ & 0.043 & - & & & & & \\
\hline 5) $\mathrm{SD}$ & -0.011 & -0.056 & 0.005 & -0.065 & $(0.747)$ & & & & \\
\hline 6) DS & -0.023 & -0.055 & 0.003 & -0.049 & $0.990^{\star * *}$ & $(0.741)$ & & & \\
\hline 7) $\mathrm{ES}$ & 0.020 & -0.051 & 0.012 & 0.102 & $0.924^{* * *}$ & $0.860^{* * *}$ & $(0.766)$ & & \\
\hline 8) $\mathrm{EP}$ & -0.039 & -0.051 & -0.009 & 0.047 & $0.255^{\star * *}$ & $0.240^{* * *}$ & $0.271^{\star * *}$ & $(0.847)$ & \\
\hline 9) $\mathrm{EI}$ & -0.04 & -0.039 & 0.066 & 0.118 & $0.139^{*}$ & 0.123 & $0.169^{\star}$ & $0.572^{\star * *}$ & $(0.810)$ \\
\hline AVE & - & - & - & - & 0.558 & 0.549 & 0.587 & 0.718 & 0.656 \\
\hline CR & - & - & - & - & 0.938 & 0.916 & 0.810 & 0.927 & 0.919 \\
\hline Mean & 1.4 & 1.64 & 2.8 & 2.49 & 3.586 & 3.593 & 3.563 & 3.663 & 3.798 \\
\hline $\mathrm{SD}$ & 0.491 & 0.623 & 0.475 & 0.661 & 0.646 & 0.645 & 0.721 & 1.163 & 0.940 \\
\hline
\end{tabular}

Note: $\mathrm{N}=216,{ }^{* *} \mathrm{p}<0.001,{ }^{* *} \mathrm{p}<0.01,{ }^{*} \mathrm{p}<0.05$, diagonal brackets are the square root of AVE, “-” means not suitable for analysis. Sex: 1 = male, 2 = female,Education: $1=$ High school, 2 = Junior college, $3=$ Undergraduate, 4 = Graduate and above. SD = Self-disclosure, DS = Descriptive Self-disclosure, ES = Evaluative Self-disclosure, EP = Entrepreneurial Passion. 
Table 3. Results of multiple regression analyses.

\begin{tabular}{|c|c|c|c|c|c|c|c|c|c|c|}
\hline \multirow{2}{*}{ Variables } & \multicolumn{4}{|c|}{ Entrepreneurial passion } & \multicolumn{6}{|c|}{ Entrepreneurial identity } \\
\hline & M 1 & M 2 & M 3 & M 4 & M 5 & M 6 & M 7 & M 8 & Ml 9 & M10 \\
\hline Sex & -0.037 & -0.032 & -0.030 & -0.039 & -0.038 & -0.035 & -0.034 & -0.040 & -0.018 & -0.019 \\
\hline Age & -0.095 & -0.084 & -0.083 & -0.091 & -0.092 & -0.086 & -0.086 & -0.090 & -0.041 & -0.042 \\
\hline Edu. & -0.047 & -0.045 & -0.044 & -0.050 & 0.030 & 0.032 & 0.032 & 0.029 & 0.056 & 0.055 \\
\hline Size & 0.076 & 0.089 & 0.084 & 0.102 & $0.149^{*}$ & $0.157^{\star}$ & 0.154 & $0.166^{*}$ & 0.109 & 0.111 \\
\hline SD & & $0.257^{\star * *}$ & & & & $0.143^{\star}$ & & & 0.006 & \\
\hline DS & & & $0.239^{\star * *}$ & & & & 0.127 & & & \\
\hline ES & & & & $0.278^{\star * *}$ & & & & $0.173^{\star}$ & & 0.025 \\
\hline EP & & & & & & & & & $0.536^{* * *}$ & $0.531^{* * *}$ \\
\hline $\mathrm{R}^{2}$ & 0.010 & 0.076 & 0.067 & 0.087 & 0.028 & 0.048 & 0.044 & 0.057 & 0.314 & 0.314 \\
\hline Adjusted $\mathrm{R}^{2}$ & -0.008 & 0.054 & 0.045 & 0.065 & 0.009 & 0.025 & 0.021 & 0.035 & 0.294 & 0.295 \\
\hline$\Delta \mathrm{R}^{2}$ & 0.010 & 0.066 & 0.057 & 0.077 & 0.028 & 0.020 & 0.016 & 0.029 & 0.266 & 0.257 \\
\hline F & 0.549 & 3.439 & 3.02 & 3.987 & 1.495 & 2.114 & 1.913 & 2.542 & 15.935 & 15.976 \\
\hline
\end{tabular}

Note: $\mathrm{N}=216,{ }^{* * *} \mathrm{p}<0.001,{ }^{* *} \mathrm{p}<0.01,{ }^{*} \mathrm{p}<0.05$. Sex: $1=$ male, $2=$ female, Education: $1=$ High school, $2=$ Junior college, 3 = Undergraduate, $4=$ Graduate and above. $\mathrm{M}=$ Model, $\mathrm{SD}=$ Self-disclosure, $\mathrm{DS}=\mathrm{De}-$ scriptive Self-disclosure, ES = Evaluative Self-disclosure, $\mathrm{EP}=$ Entrepreneurial Passion.

Hypothesis 1. Model 7 reveals that descriptive disclosure has no significant positive impact on entrepreneurial identity $(\beta=0.127, \mathrm{p}>0.05)$, so that Hypothesis $1 \mathrm{a}$ is invalid. While in Model 8 , it is clear that the evaluative disclosure has a significant positive impact on entrepreneurial identity $(\beta=0.173, \mathrm{p}<0.05)$, therefore, Hypothesis $1 \mathrm{~b}$ is established.

Intermediary effect test. Since the main effect of descriptive disclosure on entrepreneurial identity is not significant, it can be inferred without verification that Hypothesis 3a is invalid. In this study, we use the method of verifying mediation proposed by Baron and Kenny (1986) [24] to investigate the mediating effect of entrepreneurial passion in self-disclosure, evaluative disclosure and entrepreneurial identity. According to Model 2, entrepreneurial passion is positively correlated with self-disclosure $(\beta=0.257, \mathrm{p}<0.001)$. As Model 4 shows, evaluative self-disclosure has a significant positive impact on entrepreneurial passion $(\beta=0.278, \mathrm{p}<0.001)$. On the basis of Model 5, we introduce the self-disclosure and entrepreneurial passion and obtain Model 9, and it indicates that entrepreneurial passion has a significant positive impact on entrepreneurial identity $(\beta=0.536, \mathrm{p}<0.001)$, and the influence coefficient between self-disclosure and entrepreneurial identity decreased from $0.143(\mathrm{p}<0.05)$ to 0.06 ( $p>0.05)$, indicating that entrepreneurial passion plays a full mediating role between self-disclosure and entrepreneurial identity. And then, we add independent variable, evaluative self-disclosure and mediation, entrepreneurial passion to Model 5 and obtain Model 10, from which we can clarify that entrepreneurial passion has a significant positive impact on entrepreneurial identity 
( $\beta=0.531, \mathrm{p}<0.001)$, and the influence coefficient between self-disclosure and entrepreneurial identity decreased from 0.173 ( $p<0.05)$ to 0.025 ( $p>0.05$ ), indicating that entrepreneurial passion plays a full mediating role between evaluative self-disclosure and entrepreneurial identity.

In order to further examine the mediating role of entrepreneurial passion, the Process plug-in developed by Hayes (2004) [25] was used to test the significance of the mediating effect. Firstly, we test the mediation effect by the path of "self-disclosure $\rightarrow$ entrepreneurial passion $\rightarrow$ entrepreneurial identity". The Bootstrap random sampling is set to 5000 times, and the Model 4 is selected. The result shows that the indirect effect value of entrepreneurial passion is 0.1376 , and the $95 \%$ confidence interval range is [0.0624, 0.2342], excluding zero, which indicates that the entrepreneurial passion has a significant intermediary role between self-disclosure and entrepreneurial identity, and hypothesis 3 is supported. In the same way, the mediation effect test by the path of "evaluative disclosure $\rightarrow$ entrepreneurial passion $\rightarrow$ entrepreneurial identity" shows that the indirect effect value of entrepreneurial passion is 0.1476 , and the $95 \%$ confidence interval range is [0.0687, 0.2487], excluding zero, indicating that the mediating role of entrepreneurial passion between evaluative self-disclosure and entrepreneurial identity is significant, and Hypothesis $3 b$ is verified successfully.

\section{Conclusion}

This paper studies the influence mechanism of entrepreneurs' self-disclosure on the entrepreneurial identity of corporate team members, and draws the following conclusions. Firstly, entrepreneur's self-disclosure and evaluative self-disclosure have a significant positive impact on the entrepreneurial identity of corporate team members, while the descriptive self-disclosure of the entrepreneur has no significant positive impact on the entrepreneurial identity of the corporate team members. Secondly, entrepreneurial self-disclosure, descriptive self-disclosure and evaluative self-disclosure can positively influence team members' perception of entrepreneurial passion. Finally, team members' perception of entrepreneurial passion plays a significant intermediary role in the relationship between entrepreneur's self-disclosure, evaluative self-disclosure and team members' entrepreneurial identity, but the entrepreneur's descriptive self-disclosure does not.

\section{Discussion}

Based on the Social Penetration Theory and the Emotional Infection Theory, this paper explains the influence mechanism of different types of self-disclosure on entrepreneurial identity by introducing entrepreneurial passion perception from the perspective of entrepreneurs' self-disclosure. The specific research results are as follows.

Firstly, the self-disclosure of entrepreneurs plays an important role in promoting entrepreneurial identity. The transmission of emotional elements can promote the entrepreneurial identity of team members more than the transmission of 
objective information. There are two dimensions of self-disclosure-descriptive disclosure and evaluative disclosure, but data shows that only evaluative disclosure and have a significant positive impact on entrepreneurial identity, while descriptive disclosure is not related to entrepreneurial identity. The reason for this result may be that emotional identity is the main channel for Chinese entrepreneurial team members to establish contact. In the beginning of entrepreneurship, China's entrepreneurial team is mostly composed of a friendship or a period of common experience. In this team of mixed emotions, in order to gain the recognition of team members, entrepreneurs should better pay more attention to the value of emotional elements in the team. As Cardon once said, the essence of entrepreneurial identity is a positive and strong perception that may have been deeply rooted in individual emotions. As an emotional factor of entrepreneurs, evaluative disclosure has been deeply embedded in the self-disclosure of entrepreneurs. When an individual is emotionally determined to participate in an entrepreneurial activity, the influence of resources and abilities on the individual will be reduced significantly. As a consequence, the influence of entrepreneurs' self-disclosure on the team members' entrepreneurial identity is mainly through the presentation of their resources, abilities and emotions, among them, emotional elements are indispensable.

Secondly, the perception of the entrepreneurial passion of the team members plays an important role in bridging the self-disclosure and the entrepreneurial identity. With the aim to strengthen the role of self-disclosure in promoting the entrepreneurial identity of team members, entrepreneurs must pay more attention to the ways and contents of self-disclosure. Entrepreneurial passion, as an effective transforming agent, can fully transform the content and emotion of self-disclosure into the trust and expectation of entrepreneurial activities.

Therefore, entrepreneurs should not only express their entrepreneurial planning and vision to team members, but also invest abundance of emotions, and expose their energy and emotions to team members so that they can feel their entrepreneurial passion in all aspects. This perception of the entrepreneur's passion can evoke the collective memory of the entrepreneurial team, strengthen the team members' entrepreneurial identity, as well as enhance their willingness to follow, and more importantly, promote their participation and commitment to the entrepreneurial activities.

\section{Contribution}

In existing academic researches on entrepreneurial identity, many scholars only focus on to the influence of entrepreneurial resources on entrepreneurial identity of team members, that is, they pay more attention to descriptive factors such as knowledge, skills and capital of entrepreneurs. However, this paper finds that Chinese entrepreneurial teams attach more importance to emotional factors. In addition to some descriptive factors, emotional disclosure of entrepreneurs is more critical to identity. This result reveals that in the entrepreneurial environ- 
ment of China, the establishment of entrepreneurial teams is not only a combination of pure interests, but also a connection of emotions. In addition, previous studies have mainly used qualitative methods for research without exploring specific impact mechanism. This study adopts a quantitative method to clarify the influence mechanism of entrepreneurs' self-disclosure on team members' entrepreneurial identity, and enriches the research on entrepreneurial identity theory and self-disclosure.

Hence, the enlightenment of this study on entrepreneurial management practice mainly includes the following two aspects. First, entrepreneurs should conduct more emotional self-disclosure evaluation, so as to promote the emotional entrepreneurial identity of entrepreneurial team members, and then promote entrepreneurial success. For example, at the beginning of the establishment of the entrepreneurial team, because the team members have not yet formed a specific impression of the entrepreneur, entrepreneurs can obtain a good first impression by frequent self-disclosure. However, entrepreneurs should not only increase knowledge disclosure, skill disclosure and fund disclosure to effectively maintain the integrity of the entrepreneurial team, but more importantly, entrepreneurs should express their feelings in different situations and their own evaluations and other emotional information. It is revealed to the team members to gain the recognition of the team members and establish a supportive and efficient team atmosphere. In this way, the company is more likely to get a sustainable development. Second, entrepreneurs should fully realize the importance of their entrepreneurial passion for enterprise development. Emotion is an important entrepreneurial resource [18], as well as one of the important channels for entrepreneurs to obtain resources is to reasonably handle and make full use of the power of emotion. Specific to entrepreneurs, first of all, it is helpful to actively participate in social activities related to entrepreneurship, consciously cultivate innovative thinking and risk awareness, and continue to produce a happy emotional experience, so that entrepreneurs' entrepreneurial passion always maintains a high level. Secondly, it is vital to entrepreneurs to build an efficient emotional contagion mechanism, so that the entrepreneur's passion can be effectively transmitted to the team members of the company. In this regard, the team members can feel the passion of the entrepreneur through the road show, entrepreneurship financing announcement, new product release and other activities, and then it is natural for entrepreneur to consolidate the identity of the team members.

\section{Limitations and Future Research}

This study explores the influence mechanism between self-disclosure of entrepreneurs and entrepreneurial identity of team members, providing some enlightenment for future theoretical research and entrepreneurial management practice, but there are still some limitations.

One of the limitations is about the sample size and participants. In this study, 
216 valid questionnaires were finally collected, and most of the sample data were from entrepreneurial teams in Shanghai and Henan province. Therefore, the sample size was insufficient and the data had regional characteristics. As far as I am concerned, future research can expand the sample size and conduct extensive investigation and research in more regions to improve the universality of sample data and the applicability of the final theoretical model.

The other limitation is about the single level of research. In this paper, independent variables, dependent variables and mediating variables were all researched at the individual level. In the future, cross-level research methods can be considered to conduct in similar empirical research and test on entrepreneurial identity as an organizational variable from both organizational and individual levels, so as to develop a more considerable theoretical model.

\section{Conflicts of Interest}

The authors declare no conflicts of interest regarding the publication of this paper.

\section{References}

[1] Vanaelst, I., Clarysse, B. and Wright, M., et al. (2006) Entrepreneurial Team Development in Academic Spinouts: An Examination of Team Heterogeneity. Entrepreneurship Theory\& Practice, 30, 249-271. https://doi.org/10.1111/j.1540-6520.2006.00120.x

[2] Baker, C.A. (2014) T\&T Clark Handbook to Social Identity in the New Testament. Bloomsbury T\&T Clark, New York.

[3] Kašperová, E. and Kitching, J. (2014) Embodying Entrepreneurial Identity. International Journal of Entrepreneurial Behaviour \& Research, 20, 438-452.

https://doi.org/10.1108/IJEBR-07-2013-0108

[4] Baron, R.A. and Tang, J. (2011) The Role of Entrepreneurs in Firm-Level Innovation: Joint Effects of Positive Affect, Creativity, and Environmental Dynamism. Journal of Business Venturing, 26, 49-60.

https://doi.org/10.1016/j.jbusvent.2009.06.002

[5] Zou, Q. (2007) Research on the Development of Self-Disclosure Characteristics of Primary and Middle School Students. Master's Thesis, East China Normal University, Shanghai.

[6] Howe, N., Assee, J.A. and Bukowski, W.M. (1995) Self-Disclosure and the Sibling Relationship: What Did Romulus tell Remus? In: Ken J.R., Ed., Disclosure Processes in Children and Adolescents, Cambridge University Press, Cambridge, 78-99. https://doi.org/10.1017/CBO9780511527746.004

[7] Hoang, H. and Gimeno, J. (2005) Entrepreneurial Identity. Wiley Encyclopedia of Management. John Wiley \& Sons, Ltd, Chichester.

[8] Li, S., Feng, B., Li, N., et al. (2015) How Social Context Cues in Online SupportSeeking Influence Self-Disclosure in Support Provision. Communication Quarterly, 63, 586-602. https://doi.org/10.1080/01463373.2015.1078389

[9] Zhu, H.R., Zeng, C.H. and Dai, J.L. (2012) Review and Prospect of Entrepreneurial Team Research. Foreign Economy and Management, 34, 11-18.

[10] Cardon, M.S., Wincent, J., Singh, J., et al. (2005) Entrepreneurial Passion: The Na- 
ture of Emotions in Entrepreneurship. Academy of Management Annual Meeting Proceedings, 2005, G1-G6.

[11] Xie, Y.P. and Chen, X.Y. (2014) The Present Situation and Prospect of Entrepreneurial Passion Research. Foreign Economy and Management, 36, 3-11. https://doi.org/10.16538/j.cnki.fem.2014.05.001

[12] Cardon, M.S., Sudek, R., Mitteness, C., et al. (2009) The Impact of Perceived Entrepreneurial Passion on Angel Investing. Frontiers of Entrepreneurship Research, 29, $1-15$.

[13] Yitshaki, R. and Kropp, F. (2016) Entrepreneurial Passions and Identities in Different Contexts: A Comparison between High-Tech and Social Entrepreneurs. Entrepreneurship \& Regional Development, 28, 1-28. https://doi.org/10.1080/08985626.2016.1155743

[14] Schindehute, M., et al. (2006) Beyond Achievement: Entrepreneurship as Extreme Experience. Small Business Economics, 27, 349-368. https://doi.org/10.1007/s11187-005-0643-6

[15] Miller, D., Steier, L. and Breton-Miller, I.L. (2016) What Can Scholars of Entrepreneurship Learn from Sound Family Businesses? Entrepreneurship Theory \& Practice, 40, 445-455. https://doi.org/10.1111/etap.12231

[16] Baum, J.R. and Locke, E.A. (2004) The Relationship of Entrepreneurial Traits, Skill, and Motivation to Subsequent Venture Growth. Journal of Applied Psychology, 89, 587-598. https://doi.org/10.1037/0021-9010.89.4.587

[17] Cardon, M.S. (2008) Is Passion Contagious? The Transference of Entrepreneurial Passion to Employees. Human Resource Management Review, 18, 77-86. https://doi.org/10.1016/j.hrmr.2008.04.001

[18] Cooper, A.C., Woo, C.Y. and Dunkelberg, W.C. (1988) Entrepreneurs' Perceived Chances for Success. Journal of Business Venturing, 3, 97-108. https://doi.org/10.1016/0883-9026(88)90020-1

[19] Miller, D., Steier, L. and Breton-Miller, I.L. (2016) What Can Scholars of Entrepreneurship Learn From Sound Family Businesses? Entrepreneurship Theory \& Practice, 40,445-455. https://doi.org/10.1111/etap.12231

[20] Jourard, S.M. (1972) The Transparent Self. Van Nostrand Reinhold Inc.

[21] Cardon, M.S., Gregoire, D.A., Stevens, C.E., et al. (2013) Measuring Entrepreneurial Passion: Conceptual Foundations and Scale Validation. Journal of Business Venturing, 28, 373-396. https://doi.org/10.1016/j.jbusvent.2012.03.003

[22] Kašperová, E. and Kitching, J. (2014) Embodying Entrepreneurial Identity. International Journal of Entrepreneurial Behaviour and Research, 20, 438-452. https://doi.org/10.1108/IJEBR-07-2013-0108

[23] Hox, J. (2010). Multilevel analysis: Techniques and applications (2nd ed.), Routledge, New York, NY. https://doi.org/10.4324/9780203852279

[24] Baron, R.M. and Kenny, D.A. (1986) The Moderator-Mediator Variable Distinction in Social Psychological Research: Conceptual, Strategic, and Statistical Considerations. Journal of Personality and Social Psychology, 51, 1173-1182. https://doi.org/10.1037/0022-3514.51.6.1173

[25] Preacher, K.J. and Hayes, A.F. (2004) SPSS and SAS Procedures for Estimating Indirect Effects in Simple Mediation Models. Behavior Research Methods Instruments and Computers, 36, 717-731. https://doi.org/10.3758/BF03206553 